KANSAS JOURNAL of MEDICINE

\section{A Pilot and Feasibility Study to Evaluate Small and Large Bite Fascial Closure Techniques}

Clint R. Gates, M.D. ${ }^{1}$, Gina M. Berg, Ph.D., MBA²,3, Kyle B. Vincent, M.D., ${ }^{1,4}$ David L. Acuna, D.O. ${ }^{1,3,5}$, Kamran Ali, M.D. ${ }^{6,7}$ University of Kansas School of Medicine-Wichita, Wichita, KS

${ }^{1}$ Department of Surgery

${ }^{2}$ Department of Family and Community Medicine

${ }^{3}$ Wesley Medical Center, Wichita, KS

${ }^{4}$ Ascension Medical Group, Wichita, KS

${ }^{5}$ Kansas Surgical Consultants, Wichita, KS

${ }^{6}$ University of Kansas School of Medicine-Wichita, Wichita, KS

Department of Radiology

${ }^{7}$ Wichita Radiological Group, Wichita, KS

Received March 2, 2021; Accepted for publication March 31, 2021; Published online July 9, 2021 https: doi.org 10.17161/kim.voll415236

\section{ABSTRACT}

Introduction. Few randomized controlled studies have been conducted comparing a small to large fascial bite technique, yet recommendations have been made to standardize small bite closures. However, large scale randomized controlled trials require considerable effort and may benefit from a pilot study.

Methods. This multi-center randomized controlled pilot study of adult patients undergoing median laparotomy incision investigated the feasibility of studying the outcomes between small and large surgical closure techniques.

Results. Fifty of 100 planned patients consented, 32 patients completed surgery, and 19 patients completed the one-year ultrasound. Enrollment was 2.7 versus 8 patients per month pre/post addition of a study coordinator. Clinical results are summarized for feasibility demonstration purposes, but not analyzed for hypothesis testing. The total cost of the pilot study was $\$ 19,152.50$ and took 22 months from first surgery to final one-year ultrasound.

Conclusions. This feasibility assessment demonstrated the complexity of planning a large-scale randomized trial evaluating small and large bite surgical closure technique. To expand this pilot study to a full scaled sample size study would require dedicated personnel and large grant funding. Kans J Med 2021;14:163-169

\section{INTRODUCTION}

The incidence of incisional hernia following a median laparotomy incision is $11-20 \% .^{1-4}$ Incisional hernias can be symptomatic or life threatening when they incarcerate, strangulate, or lead to bowel obstructions and may require surgical repair ( $45 \%$ chance of recurrence) ${ }^{5}$ and incurs cost. ${ }^{6}$ Risk factors include diabetes, malignancy, wound infection, malnutrition, previous laparotomy, use of corticosteroids, and surgical technique., ${ }^{2,37}$ Modifiable surgical technique components include suture material, ${ }^{8}$ running versus interrupted suture, ${ }^{3,9-12}$ and suture length to wound length ratio (SL:WL). ${ }^{8,12-15}$ The SL:WL can vary based on suture bite width, advancement length, and applied tension. A larger bite incor- porates more tissue within the suture line distributing tension over more tissue, theoretically decreasing tissue strangulation. However, a larger bite incorporates tissue that offers no tensile strength allowing the suture material to cut through and loosening the closure. A smaller bite aims to grab precisely only the fascia, the tissue that provides the tensile strength. ${ }^{16}$ Small bite versus large bite was studied in the Netherlands (the STITCH Trial) and demonstrated an $8 \%$ absolute reduction in the occurrence of incisional hernia at one year in the small bite group. ${ }^{17}$ The authors concluded that the small bite technique should become standard clinical practice closure technique for midline incisions.

Clinical practice guidelines to standardize care are developed by a systematic review of multiple studies rather than a single study. ${ }^{18}$ The STITCH Trial was a randomized controlled trial (RCT) of 560 patients, ten surgical centers, from 2009 to $2012,{ }^{17}$ and has been criticized for variability in SL:WL, ${ }^{19}$ non-standardized suture material and needles, ${ }^{20}$ and length of follow-up period. ${ }^{21}$ The feasibility of replicating large multi-center RCTs to corroborate findings can be assessed by a pilot trial to reveal the challenges of study protocols. ${ }^{22-24}$ Jeray et al. ${ }^{22}$ indicated objectives of a pilot study include: 1) integrity of study protocol; 2) consent and recruitment; 3) acceptability of intervention/randomization; 4) safety; 5) economically justifiable; and 6) data collection and management. Pilot studies also may include a feasibility assessment to make a determination to proceed with the full scale study ${ }^{22,23,25,26}$ and may de-risk large scale funding. ${ }^{27}$

This was a multi-center pilot study to assess the feasibility of replicating the STITCH Trial. ${ }^{17}$ The primary outcomes were to follow objectives as previously listed by Jeray et al. ${ }^{22}$ Due to low sample size of pilot data, the clinical data are presented only to demonstrate Jeray's objective \#6.

\section{METHODS}

This feasibility study was approved by the Wichita Medical Research and Education Foundation, Via Christi St. Francis, University of Kansas School of Medicine-Wichita, and Wichita State University Institutional Review Boards. All participants underwent the informed consent process and participation was voluntary.

Participants. Patients undergoing surgery at two tertiary hospitals were eligible if adult (age 18 - 75) and scheduled for a potential operation through a midline incision. Exclusion criteria included: previous incisional hernia or fascial dehiscence with secondary healing after midline incision, pregnant, body mass index (BMI) over 50, laparotomy within one year, expected to live less than 24 hours, systolic blood pressure

$90 \mathrm{mmHg}$, and an American Society of Anesthesiologists (ASA) Physical Status score $\geq 4 .{ }^{28}$ Study participants were to be enrolled in their clinic office or in the hospitals. Enrollment was monitored monthly.

Procedure. Data were collected at: Stage 1) Enrollment (pre-surgery, patient demographics); Stage 2) Surgery (closure details); Stage 3) Discharge (hospital course); Stage 4) Six week post-operative (outpatient follow-up, complications); and Stage 5) One-year ultrasound (presence or absence of hernia). Patients were blinded to closure technique and closure type was revealed to the surgeon at the time of fascial closure. Post-operative ultrasonography was performed at one year by a radiologist blinded to closure technique. Participants were offered a \$30 incentive for completing Stage 4 and a $\$ 100$ incentive for completing Stage 5. There was no charge for the one-year ultrasound. 
Protocol education was provided to staff at each facility, including videos demonstrating the separate closure techniques. The small bite technique used $0.5 \mathrm{~cm}$ bite width and $0.5 \mathrm{~cm}$ inter-suture spacing using 2-0 PDS II suture on an SH 26 mm taper needle (Product Number: Z317, Ethicon, Cincinnati, OH). The large bite closure technique used $1 \mathrm{~cm}$ bite width and $1 \mathrm{~cm}$ inter-suture spacing with 1 PDS ${ }^{\circledast} \mathrm{II}$ suture on a CT-1 36 mm taper needle (Product Number: Z347, Ethicon, Cincinnati, $\mathrm{OH})$. Running suture was used in all participants and nine knots were used at each of the three tie-off locations (center and both ends). Remaining suture was retained for SL:WL ratio calculation. The wound length and number of bites taken were recorded and calculated to verify that the proper technique was employed.

Statistical Analysis. Feasibility and clinical findings were summarized with descriptive statistics using means (standard deviations) and frequencies (percentages) as appropriate. This feasibility study was not designed to conduct clinical hypothesis testing; thus, no comparison statistics are reported.

\section{RESULTS}

Enrollment. Figure 1 demonstrates participant attrition. Only 50 of the planned 100 participants were enrolled in 10 months. Of those, 18 (36\%) were excluded for ineligibility (no midline incision), surgeon discretion, missing surgery data, or complications (return to the operating room, anastomotic leak, or missing data). Of the 32 patients who completed surgery, 13 (41\%) participants were randomized into the small bite group and 19 (59\%) were randomized into the large bite group. Thirteen participants were lost to one-year ultrasound follow-up. Thus, the final ultrasound sample was 19 (38\%). In the final ultrasound group $(n=19)$, eight (42.1\%) had been randomized into the small bite group and eleven (57.8\%) in the large bite group.

Clinical Data Only for Feasibility Demonstration Purposes. Table 1 describes the participant demographics. Of the 32 patients that completed the surgery, 14 (40\%) were male and the average age was 56.9 years (SD 13.1). Of the 19 participants that completed the ultrasound, there were eight males (42\%) and the average age was 61.8 years (SD 9.4).

Table 2 describes surgery data. The mean incision length was 19.9 $\mathrm{cm}$ and $11.9 \mathrm{~cm}$ in the small and large bite groups, respectively. Mean stitches per centimeter of incision were $2.2 \mathrm{~cm}$ for small bite and $1.1 \mathrm{~cm}$ for large bite group. Mean suture length/wound length ratios were 3.6 $\mathrm{cm}$ and $5.6 \mathrm{~cm}$ for the small and large bite groups, respectively.

Of the 32 participants that completed surgery, one received a blood transfusion and one had a surgical site infection, both in the large bite group (Table 3). One patient who completed surgery expired due to reasons unrelated to the study. The mean hospital length of stay was 7.4 days and 6.9 days for the small and large bite groups, respectively. One patient (5.2\%) required intensive care unit admission and one (5.2\%) was readmitted for suspected anastomotic leak, both in the large bite group.

Two complications were reported in the post-operative clinic visits (Table 4): one wound infection and one superficial skin dehiscence, both were in the large bite group. There were no incisional hernias appreciated on physical exam for either group. Nineteen of the 33 participants that completed the surgery also completed the one-year ultrasound (Table 5). The average maximum distance between the
KANSAS JOURNAL of MEDIC INE SMALLAND LARGE BITE FASCIAL CLOSURE TECHNIQUES

continued.

rectus muscles was $2.7 \mathrm{~cm}$ in the small bite group and $2.2 \mathrm{~cm}$ in the large bite group. Radiology readings indicated that 19 (100\%) had an intact linea alba, but there was one (5.2\%) fascial defect in the small bite group. Clinical data were presented only to demonstrate Jeray's objective \#6.22

Table 1. Study participant demographics and pre-operative characteristics.

\begin{tabular}{|c|c|c|c|}
\hline & & \multicolumn{2}{|c|}{$\begin{array}{c}\text { Stage } 5 \text { (US) completed } \\
(\mathrm{N}=19)\end{array}$} \\
\hline & $(\mathrm{N}=32)$ & $\begin{array}{l}\text { Small } \\
(\mathrm{n}=8)\end{array}$ & $\begin{array}{l}\text { Large } \\
(\mathrm{n}=11)\end{array}$ \\
\hline Age, mean (SD) & $56.94(13.1)$ & $60.8(10.8)$ & $62.6(8.7)$ \\
\hline Height, cm, mean (SD) & $169.7(9.2)$ & $168.5(11.6)$ & $170.1(9.0)$ \\
\hline Weight, kg, mean (SD) & $77.4(18.9)$ & $75.5(12.1)$ & $85.9(20.4)$ \\
\hline \multirow[t]{2}{*}{ BMI, mean (SD) } & $27.3(6.3)$ & $28.0(5.8)$ & $29.5(6.4)$ \\
\hline & $f(\%)$ & $f(\%)$ & $\mathrm{f}(\%)$ \\
\hline Sex, male & $14(40.0)$ & $3(37.5)$ & $5(45.5)$ \\
\hline \multicolumn{4}{|l|}{ Medical history } \\
\hline Current smoker & $9(28.1)$ & 0 & $4(36.4)$ \\
\hline History of COPD & $3(9.4)$ & 0 & $1(9.1)$ \\
\hline Diabetes mellitus & $10(31.3)$ & $4(50.0)$ & $3(27.3)$ \\
\hline Heart disease & $3(9.4)$ & $2(25.0)$ & $1(9.1)$ \\
\hline \multicolumn{4}{|l|}{ Pre-operative } \\
\hline Radiation therapy & $4(12.5)$ & $1(12.5)$ & $1(9.1)$ \\
\hline Chemotherapy & $5(15.6)$ & $1(12.5)$ & $1(9.1)$ \\
\hline Corticosteroids & $2(6.3)$ & 0 & $1(9.1)$ \\
\hline \multicolumn{4}{|l|}{ Previous procedures } \\
\hline Abdominal operations & $17(53.1)$ & $4(50.0)$ & $6(54.5)$ \\
\hline Other hernias & $2(6.3)$ & 0 & $1(9.1)$ \\
\hline \multicolumn{4}{|l|}{ ASA classification } \\
\hline 1 Normal healthy & $21(65.6)$ & $5(62.5)$ & $9(81.8)$ \\
\hline $\begin{array}{l}2 \text { Mild systemic } \\
\text { disease }\end{array}$ & $6(18.8)$ & $1(12.5)$ & 0 \\
\hline $\begin{array}{l}3 \text { Severe systemic } \\
\text { disease }\end{array}$ & $4(12.5)$ & $1(12.5)$ & $2(18.2)$ \\
\hline
\end{tabular}

Note: Percentages may not total $100 \%$ due to missing patient data. Patients not eligible if pregnant, previous incisional hernia, laparotomy within past year, BMI over 50, or moribund. Other hernias include umbilical or ventral hernia in distant past. ASA = American Society of Anesthesiologists (http://www.asahq. org/resources/clinical-information/asa-physical-statusclassification-system). 


\section{KANSAS JOURNAL of MEDICINE}

\section{SMALL AND LARGE BITE FASCIAL CLOSURE}

\section{TECHNIQUES}

continued.

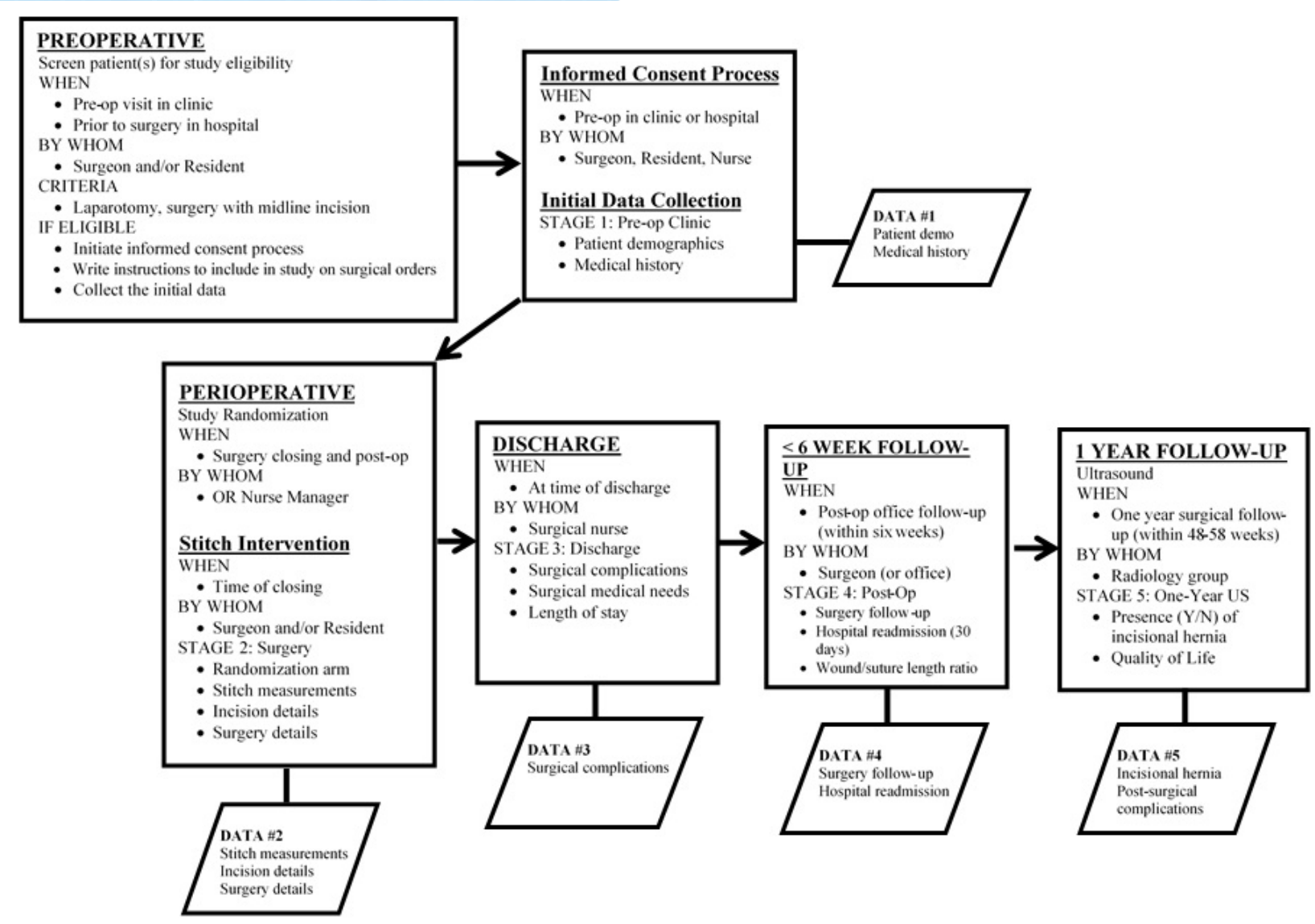

Figure 1. BITES (Better Incisional closure Technique Evolution in Surgery) study flowchart.

Table 2. Operative data.

\begin{tabular}{|c|c|c|c|c|}
\hline & \multicolumn{2}{|c|}{$\begin{array}{l}\text { Surgery completed } \\
\qquad(\mathrm{N}=32)\end{array}$} & \multicolumn{2}{|c|}{$\begin{array}{l}\text { Ultrasound completed } \\
\qquad(\mathrm{N}=19)\end{array}$} \\
\hline & $\begin{array}{l}\text { Small } \\
(\mathrm{n}=13)\end{array}$ & $\begin{array}{l}\text { Large } \\
(n=19)\end{array}$ & $\begin{array}{l}\text { Small } \\
(\mathrm{n}=8)\end{array}$ & $\begin{array}{l}\text { Large } \\
(\mathrm{n}=11)\end{array}$ \\
\hline \multicolumn{5}{|l|}{ Facility } \\
\hline Hospital 1 & $2(15.4)$ & $7(36.8)$ & $1(12.5)$ & $6(54.5)$ \\
\hline Hospital 2 & $11(84.6)$ & $12(63.2)$ & $7(87.5)$ & $5(45.5)$ \\
\hline \multicolumn{5}{|l|}{ Closure details } \\
\hline Number of stitches, $f(\%)$ & $40.6(16.1)$ & $15.1(11.0)$ & $43.5(15.4)$ & $13.6(7.6)$ \\
\hline Length of incision, mean (SD) & $18.7(6.3)$ & $14.2(7.3)$ & $19.9(5.5)$ & $11.9(6.3)$ \\
\hline Range of incision & $6.0-26.0$ & $3.5-28.0$ & $8.0-25.0$ & $6.0-25.00$ \\
\hline Stitches per incision $\mathrm{cm}$ & $2.2(.5)$ & $1.2(.2)$ & $2.2(.57)$ & $1.14(.2)$ \\
\hline Range of stitch per incision $\mathrm{cm}$ & $1.6-3.0$ & $1.0-1.6$ & $1.64-3.06$ & $1.0-1.47$ \\
\hline Length of suture, mean (SD) & $72.3(23.4)$ & $62.9(18.9)$ & $84.0(20.1)$ & $55.4(17.7)$ \\
\hline SL:WL, mean (SD)* & $3.8(1.0)$ & $4.5(1.1)$ & $3.6(.97)$ & $5.6(2.6)$ \\
\hline SL:WL range & $2.7-5.9$ & $3.1-7.7$ & $2.68-4.86$ & $3.30-11.88$ \\
\hline \multicolumn{5}{|l|}{ Surgical details } \\
\hline EBL (cc), mean (SD) & $188.8(206.8)$ & $97.9(96.4)$ & $85.6(60.0)$ & $9(81.8)$ \\
\hline Antibiotic prophylaxis, $f(\%)$ & $13(100.0)$ & $19(100.0)$ & $8(100.0)$ & $11(100)$ \\
\hline Thrombosis prophylaxis, $f(\%)$ & $8(61.5)$ & $15(78.9)$ & $5(62.5)$ & $9(81.8)$ \\
\hline Drains, $f(\%)$ & $6(46.2)$ & $6(31.6)$ & $2(25.0)$ & $3(30.0)$ \\
\hline Death during surgery, $f(\%)$ & 0 & 0 & 0 & 0 \\
\hline
\end{tabular}

Note: *Three patients excluded due to missing suture pieces. 
Table 3. Hospital course.

\begin{tabular}{|c|c|c|c|c|}
\hline & \multicolumn{2}{|c|}{$\begin{array}{c}\text { Surgery completed } \\
(\mathrm{N}=32)\end{array}$} & \multicolumn{2}{|c|}{$\begin{array}{l}\text { Ultrasound completed } \\
\qquad(\mathrm{N}=19)\end{array}$} \\
\hline & $\begin{array}{l}\text { Small } \\
(\mathrm{n}=13)\end{array}$ & $\begin{array}{l}\text { Large } \\
(\mathrm{n}=19)\end{array}$ & $\begin{array}{l}\text { Small } \\
(\mathrm{n}=8)\end{array}$ & $\begin{array}{l}\text { Large } \\
(\mathrm{n}=11)\end{array}$ \\
\hline \multicolumn{5}{|l|}{ Post-operative complications } \\
\hline Ileus & $4(30.8)$ & $7(36.8)$ & $2(25.0)$ & $6(54.5)$ \\
\hline Blood transfusion & 0 & $1(5.2)$ & 0 & 0 \\
\hline Surgical site infection & 0 & $1(5.2)$ & 0 & 0 \\
\hline Wound hematoma & 0 & 0 & 0 & 0 \\
\hline Pulmonary infection & 0 & 0 & 0 & 0 \\
\hline Ventilation & 0 & 0 & 0 & 0 \\
\hline Corticosteroids & 0 & 0 & 0 & 0 \\
\hline Other & 0 & $1(5.2)$ & & \\
\hline \multicolumn{5}{|l|}{ Hospital course } \\
\hline Hospital length of stay & $7.5(4.3)$ & $6.3(4.5)$ & $7.38(4.6)$ & $6.9(5.7)$ \\
\hline ICU admission, $f(\%)$ & $1(7.7)$ & $2(10.5)$ & 0 & $1(9.1)$ \\
\hline ICU length of stay & $5.0(0.0)$ & $3.5(2.1)$ & 0 & $5.0(0.0)$ \\
\hline Readmission with 30 days, $f(\%)$ & 0 & $2(10.5)^{1}$ & 0 & $1(9.1)^{2}$ \\
\hline Death post surgery & 0 & 0 & & \\
\hline
\end{tabular}

${ }^{1}$ Anastomotic leak; abdominal pain/constipation.

${ }^{2}$ Anastomotic leak and suspected anastomotic leak.

Table 4. Six-week post-operative complications.

\begin{tabular}{|l|c|c|c|c|}
\hline & \multicolumn{2}{|c|}{$\begin{array}{c}\text { Surgery completed } \\
(\mathrm{N}=32)\end{array}$} & \multicolumn{2}{c|}{$\begin{array}{c}\text { Ultrasound completed } \\
(\mathrm{N}=19)\end{array}$} \\
\hline & $\begin{array}{c}\text { Small } \\
(\mathrm{n}=13)\end{array}$ & $\begin{array}{c}\text { Large } \\
(\mathrm{n}=19)\end{array}$ & $\begin{array}{c}\text { Small } \\
(\mathrm{n}=8)^{1}\end{array}$ & $\begin{array}{c}\text { Large } \\
(\mathrm{n}=11)\end{array}$ \\
\hline Incisional hernia (palpated) & 0 & 0 & 0 & 0 \\
\hline Wound dehiscence & 0 & & 0 & 0 \\
\hline Wound infection & 0 & $1(5.2)^{2}$ & 0 & $1(9.1)$ \\
\hline Seroma formation & 0 & 0 & 0 & 0 \\
\hline Other wound problems & 0 & $1(5.2)^{3}$ & 0 & $1(9.1)$ \\
\hline
\end{tabular}

Note: Frequencies (\%).

${ }^{1}$ One of the ultrasound (small bite) patients did not attend the post-operative clinic visit.

${ }^{2}$ Superficial.

${ }^{3}$ Superficial skin dehiscence.

Table 5. One-year ultrasound follow-up contacts $(\mathrm{n}=32)$.

\begin{tabular}{|l|c|c|}
\hline & \multicolumn{2}{|c|}{$\begin{array}{c}\text { Ultrasound eligible } \\
\mathrm{N}=19)\end{array}$} \\
\hline & $\begin{array}{c}\text { Attrition } \\
(\mathrm{n}=13,40.6 \%)\end{array}$ & $\begin{array}{c}\text { Completed } \\
(\mathrm{n}=19,59.3 \%)\end{array}$ \\
\hline Letters returned, $f(\%)$ & $3(23.0)$ & $1(5.3)^{1}$ \\
\hline Number of letters sent, mean (SD) & $2.9(.3)$ & $1.4(.8)$ \\
\hline Number of letters, $f(\%)$ & & \\
\hline 1 & 0 & $14(73.7)$ \\
\hline 2 & $1(7.7)^{2}$ & $2(10.5)$ \\
\hline 3 & $12(92.3)$ & $3(15.8)$ \\
\hline
\end{tabular}

${ }^{1}$ Patient called to follow-up.

${ }^{2}$ Letter returned before third letter sent. 
KANSAS JOURNAL of MEDICINE

SMALLAND LARGE BITE FASCIAL CLOSURE

TECHNIQUES

continued.

Feasibility Study Development. This study required the approval of four IRBs. Study design, logistic planning, and grant and IRB application preparation required over 16 team meetings. Twelve education sessions were conducted. The planning phase took 18 months until the first patient was enrolled.

Study Personnel. This was a surgery resident directed study. Three research personnel contributed to grant and protocol development. Three surgeons/attendings served as principal investigators. Twentytwo surgeons agreed to participate in the study, 14 participated, and the number of cases per surgeon ranged from one to eight. Two surgeons performed nearly $40 \%$ of the cases. Three physician assistant students assisted with suture measurement and data entry. One medical student was hired as study coordinator. The number of clinic and operation room nurses and managers who were educated on the study protocol and participated were not collected. Radiology technicians performed the ultrasounds which were assessed by an attending radiologist.

Recruitment. Only half (50/100) of the expected participants were enrolled at ten months, thus new participant enrollment was terminated (Figure 2). Early enrollment in surgeon offices was not successful. The monthly average enrollment was 2.7 which increased to 8 after a parttime study coordinator was hired as shown in Figure 3. The study took 22 months from the first surgery until the last one-year ultrasound was completed.

Participant Attrition. Figure 2 demonstrates participant attrition. Sixty-four percent (32/50) completed surgery. Only 19/50 (38\%) of those enrolled completed the entire study. Three follow-up invitation letters were sent to the 13 participants who were lost to ultrasound follow-up.

Costs. Table 6 lists the costs of the current feasibility study and projected costs extrapolated to the large-scale sample sizes based on actual costs.

\section{DISCUSSION}

This was a surgery resident-driven feasibility assessment of a randomized controlled trial evaluating small and large bite closure techniques. Clinical results were reported for demonstration only as it is not appropriate to interpret feasibility data for hypothesis testing; thus, this discussion is focused on the feasibility assessment according to Jeray et al. ${ }^{22}$

Integrity of Study Protocol. All personnel received protocol education; however, investigators suspected there may have been a few inaccuracies in data collection (e.g., Stage 5: One-year ultrasound: intact linea alba noted with an incisional hernia). Surgical technique was evaluated and deemed adequate by a preliminary assessment at six months evaluating the SL:WL ratio and the number of stitches placed per centimeter of wound length.

Consent and Recruitment. The plan was for participant enrollment to be performed during pre-operative clinic visits and when not successful by operation room staff and/or surgery residents. Both options required changes in staff workflow. When low enrollment was noted, a study coordinator was hired. At ten months, only half of the planned 100 participants had been enrolled, thus enrollment was terminated due to time constraints. Barriers to successful enrollment included case volume availability predictions that were too high, but primarily, expectations of the volunteer staff were too much.

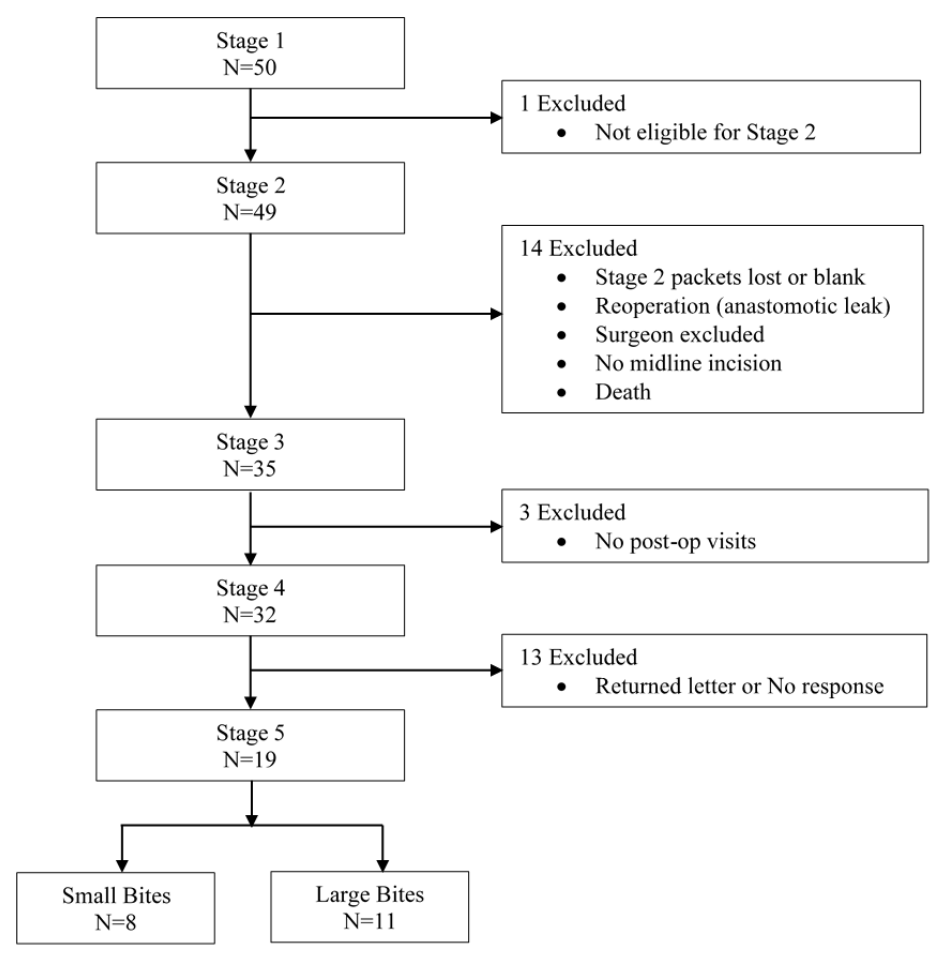

Figure 2. STARD diagram for flow of patients.

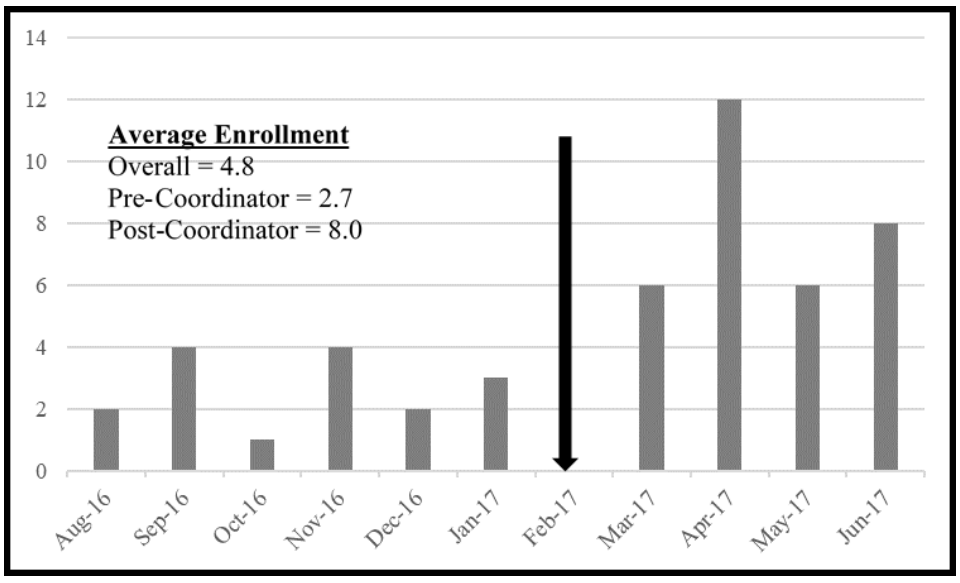

Figure 3. Participant enrollment with and without study coordinator.

Acceptability of Intervention/Randomization. One surgeon excluded a patient at the point of randomization based on patient characteristics, even though he had participated with other patients. Had this been the full-scale study, the exclusion would have been reviewed and surgeons re-educated to prevent potential bias.

Safety. There were no adverse events relevant to this study. The single incisional hernia observed was within the reported incidence (11$20 \%$ ) of incisional hernia following a median laparotomy incision. ${ }^{1-4}$ One patient expired, unrelated to study.

Economically Justifiable. Costs were extrapolated from this study ( $\mathrm{n}=19)$ to the sample size indicated $(\mathrm{n}=576)$ in the full scale STITCH Trial $^{17}$ or 690 estimated by sample size calculation. Sample size was calculated on the incidence of incisional hernia in the STITCH Trial ${ }^{17}$ ( $21 \%$ large bite vs. $13 \%$ small bite), study power was set at $80 \%$, and alpha was set at $5 \%$. A total of 690 patients are needed for a large-scale 
RCT. The projected full-scale study was estimated to cost $\$ 586,954.65$ $(\mathrm{N}=576)$ or $\$ 704,050.00(\mathrm{~N}=690)$. The cost likely was inflated due to short-term process inefficiencies, but also under-reported as all academic support was provided in-kind. The original STITCH Trial, having 560 patients and ten sites, took three years. ${ }^{17}$ Replicating with only two sites, such as this feasibility study, would take significantly longer.

Table 6. Projection for full scale study extrapolated from $19(38 \%)$ patients completed.

\begin{tabular}{|l|c|c|c|}
\hline & $\begin{array}{c}\text { Current feasibility } \\
(\mathrm{N}=19)\end{array}$ & $\begin{array}{c}\text { STITCH } \\
(\mathrm{N}=576)\end{array}$ & $\begin{array}{c}\text { Estimated } \\
\text { sample size } \\
(\mathrm{N}=690)\end{array}$ \\
\hline $\begin{array}{l}\text { Projected enrollment (based } \\
\text { on 62\% feasibility attrition) }\end{array}$ & 50 & 1,515 & 1,863 \\
\hline Costs & $\$ 102.50$ & $\$ 3,105.75$ & $\$ 3,819.15$ \\
\hline $\begin{array}{l}\text { Data collection packets (5 } \\
\text { packets per enrolled) }\end{array}$ & $\$ 960.00$ & $\$ 29,070.00$ & $\$ 35,760.00$ \\
\hline $\begin{array}{l}\text { Stage } 4 \text { incentives (actual } \\
\$ 30^{*} 64 \% \text { enrolled) }\end{array}$ & $\$ 1,900.00$ & $\$ 57,600.00$ & $\$ 69,000.00$ \\
\hline $\begin{array}{l}\text { Stage } 5 \text { incentives (actual } \\
\$ 100^{*} 100 \% \text { completed) }\end{array}$ & $\$ 1,900.00$ & $\$ 57,600.00$ & $\$ 69,000.00$ \\
\hline $\begin{array}{l}\text { Stage } 5 \text { ultrasounds (actual } \\
\$ 100^{* 100 \%} \text { completed) }\end{array}$ & $\$ 14,500.00$ & $\$ 439,578.90$ & $\$ 526,470.00$ \\
\hline $\begin{array}{l}\text { Coordinator cost }(\$ 753 \\
\text { per } 19 \text { completed) }\end{array}$ & $\$ 19,362.50$ & $\$ 586,954.65$ & $\$ 704,049.15$ \\
\hline $\begin{array}{l}\text { Total costs (projected for } \\
\text { replication) }\end{array}$ & & \\
\hline
\end{tabular}

Note: Not all patients who completed Stage 4 (Post-operative) completed Stage 5 (Ultrasound). Coordinator cost included enrollment and data entry.

Data Collection and Management. Data collection was not ideal and required frequent reliability checks. Stage 3 (Surgery) data collection packets were lost resulting in excluding consented patients from the study. Stage 4 (Post-operative) data were not collected consistently during the post-operative visit and instead abstracted from the patient medical record. Data management was effective to report the pilot statistics presented here.

Limitations. Pilot studies are not recommended for calculating sample sizes or response rates for large scale studies. ${ }^{24}$ Hypothesis testing is not valid without an appropriate sample size. This feasibility study replicated the STITCH Trial in using two different needles and suture materials, a criticism noted by Gajjar and Shafi. ${ }^{20}$

\section{CONCLUSIONS}

This pilot study, with feasibility assessment, was a good demonstration of potential issues in planning a large scale randomized controlled multi-center trial, in this case evaluating small and large bite surgical closure techniques. As planned, there were not enough data to derive any clinical conclusions and were presented only for feasibility demonstration. This was time and resource intensive and required dedicated study personnel for enrollment success. To expand this pilot study to a full-scaled sample size appropriate study would require dedicated personnel and large grant funding. Depending on in-kind resources likely would not result in a successful and timely study. These results did not preclude the necessity of a confirmation study to generate evidence supported guidelines for best practice closure technique.
KANSAS JOURNAL of MEDIC INE

SMALLAND LARGE BITE FASCIAL CLOSURE

TECHNIQUES

continued.

\section{ACKNOWLEDGEMENTS}

The authors would like to acknowledge the following supporters of this study: Felecia Lee, Ph.D., Ashley Hervey, M.Ed., Jimmie Stewart, M.D., Sue Nyberg, PA-C, MPH, Megan Holick, PA-C, Lauren Simmons, PA-C, Calder Young, PA-C, Rita Railing, Jacqueline Osland, M.D., Noel Sanchez, M.D., Ali Ahmad, M.D., Paul Harrison, M.D., William Waswick, M.D., Lindsey Strader, D.O., Michael Porter, M.D., Aaron Nilhas, M.D., J.L. Smith, M.D., Brent Lancaster, M.D., Jeremy Howes, M.D., and the University of Kansas School of Medicine-Wichita, Wesley Medical Center, Via Christi St Francis Hospital, Wichita Surgical Specialists, and Kansas Surgical Consultants.

This study was funded by a grant from the Kansas Biosciences Authority via the University of Kansas School of Medicine-Wichita as well as funds from Wesley Medical Center Trauma Services.

\section{REFERENCES}

${ }^{1}$ Mudge M, Hughes LE. Incisional hernia: A 10 year prospective study of incidence and attitudes. Br J Surg 1985; 72(1):70-71. PMID: 3155634.

${ }^{2}$ Sugerman HJ, Kellum JM Jr., Reines HD, DeMaria EJ, Newsome HH, Lowry JW. Greater risk of incisional hernia with morbidly obese than steroid-dependent patients and low recurrence with prefascial polypropylene mesh. Am J Surg 1996; 171(1):80-84. PMID: 8554156.

${ }^{3}$ van 't Riet M, Steyerberg EW, Nellensteyn J, Bonjer HJ, Jeekel J. Metaanalysis of techniques for closure of midline abdominal incisions. Br J Surg. 2002; 89(11):1350-1356. PMID: 12390373.

${ }^{4}$ Wissing J, van Vroonhoven TJ, Schattenkerk ME, Veen HF, Ponsen RJ, Jeekel J. Fascia closure after midline laparotomy: Results of a randomized trial. Br J Surg 1987; 74(8):738-741. PMID: 3307992.

${ }^{5}$ Geçim IE, Koçak S, Ersoz S, Bumin C, Aribal D. Recurrence after incisional hernia repair: Results and risk factors. Surg Today 1996; 26(8):607-609. PMID: 8855493.

6 Park AE, Roth JS, Kavic SM. Abdominal wall hernia. Curr Probl Surg 2006; 43(5):326-375. PMID: 16679124.

7 Ellis H, Gajraj H, George CD. Incisional hernias: When do they occur? Br J Surg 1983; 70(5):290-291. PMID: 6850263.

8 Israelsson LA, Jonsson T. Suture length to wound length ratio and healing of midline laparotomy incisions. Br J Surg 1993; 80(10):1284-1286. PMID: 8242299.

9 Ceydeli A, Rucinski J, Wise L. Finding the best abdominal closure: An evidence-based review of the literature. Curr Surg 2005; 62(2):220-225. PMID: 15796944.

${ }^{10}$ Hodgson NC, Malthaner RA, Ostbye T. The search for an ideal method of abdominal fascial closure: A meta-analysis. Ann Surg 2000; 231(3):436-442. PMID: 10714638.

11 Rucinski J, Margolis M, Panagopoulos G, Wise L. Closure of the abdominal midline fascia: Meta-analysis delineates the optimal technique. Am Surg 2001; 67(5):421-426. PMID: 11379640.

${ }^{12}$ Weiland DE, Bay RC, Del Sordi S. Choosing the best abdominal closure by meta-analysis. Am J Surg 1998; 176(6):666-670. PMID: 9926810.

${ }_{13}$ Israelsson LA, Jonsson T. Overweight and healing of midline incisions: The importance of suture technique. Eur J Surg 1997; 163(3):175-180. PMID: 9085058.

${ }^{14}$ Israelsson LA, Jonsson T, Knutsson A. Suture technique and wound healing in midline laparotomy incisions. Eur J Surg 1996; 162(8):605-609. PMID: 8891617.

${ }_{15}$ Jenkins TP. The burst abdominal wound: A mechanical approach. Br J Surg 1976; 63(11):873-876. PMID: 137024.

${ }^{16}$ Harlaar JJ, van Ramshorst GH, Nieuwenhuizen J, et al. Small stitches with small suture distances increase laparotomy closure strength. Am J Surg 2009; 198(3):392-395. PMID: 19285296.

${ }_{17}$ Deerenberg EB, Harlaar JJ, Steyerberg EW, et al. Small bites versus large bites for closure of abdominal midline incisions (STITCH): A double-blind, multicentre, randomised controlled trial. Lancet 2015; 386(10000):12541260. PMID: 26188742. 


\section{KANSAS JOURNAL of MEDICINE}

SMALLAND LARGE BITE FASCIAL CLOSURE

TECHNIQUES

continued.

${ }^{18}$ Lim W, Arnold DM, Bachanova V, et al. Evidence-based guidelines--An introduction. Hematology Am Soc Hematol Educ Program 2008; 26-30. PMID: 19074050.

19 Fujita T. Closure of abdominal midline incisions: STITCH Trial. Lancet 2016;387(10018):534. PMID: 26867444.

${ }^{20}$ Gajjar K, Mahmood S. Closure of abdominal midline incisions: STITCH Trial. Lancet 2016; 387(10018):534-535. PMID: 26867443.

${ }^{21}$ Hayashi K, Ozaki A, Tanimoto T. Closure of abdominal midline incisions: STITCH Trial. Lancet 2016; 387(10018):535. PMID: 26867446.

22 Jeray KJ, Tanner SL. Pilot randomized trials: Is there a need? J Bone Joint Surg Am 2012; 94 (Suppl 1):15-18. PMID: 22810441.

23 Arnold DM, Burns KE, Adhikari NK, et al. The design and interpretation of pilot trials in clinical research in critical care. Crit Care Med 2009; 37(1 Suppl):S69-74. PMID: 19104228.

${ }^{24}$ Cope DG. Conducting pilot and feasibility studies. Oncol Nurs Forum 2015; 42(2):196-197. PMID: 25806886.

${ }^{25}$ Whitehead AL, Sully BG, Campbell MJ. Pilot and feasibility studies: Is there a difference from each other and from a randomised controlled trial? Contemp Clin Trials 2014; 38(1):130-133. PMID: 24735841.

${ }^{26}$ Eldridge SM, Lancaster GA, Campbell MJ, et al. Defining feasibility and pilot studies in preparation for randomised controlled trials: Development of a conceptual framework. PLoS One 2016; 11(3):e0150205. PMID: 26978655.

${ }^{27}$ Morgan B, Hejdenberg J, Hinrichs-Krapels S, Armstrong D. Do feasibility studies contribute to, or avoid, waste in research? PLoS One 2018; 13(4):e019595l. PMID: 29684043.

28 American Society of Anesthesiologists. ASA Physical Status Classification System. October 15, 2014.. https://www.asahq.org/standards-and-guidelines/asa-physical-status-classification-system. Accessed April 9, 2019.

Keywords: pilot study, surgical closure techniques, suture techniques, treatment outcome, abdominal wound closure techniques 